\title{
Distribution of antibiotics in the vadose zone in Xiaodian Sewage Irrigation Area, Northern China
}

\author{
Jiale $\mathrm{Li}^{1,2,3^{*}}$, Yihui Dong ${ }^{1,3}$, Zhanxue $\mathrm{Sun}^{1}$, and Huijun Ding $^{4}$ \\ ${ }^{1}$ East China University of Technology, Nanchang, 330013, China \\ ${ }^{2}$ Beijing Research Institute of Uranium Geology, Beijing, 100029, China \\ ${ }^{3}$ China University of Geosciences, Wuhan, 430074, China \\ ${ }^{4}$ Jiangxi Institute of Water Sciences, Nanchang, 330029, China
}

\begin{abstract}
Because of water shortages, the Xiaodian area in northern China had a long history of sewage irrigation. To study the distribution of antibiotics in the vadose zone, a sewage sample and 5 soil profiles were collected and analyzed. Macrolides and Fluoroquinolones were the main antibiotics observed in the shallow vadose zone. The contents of antibiotics in the soil profile nearby the sewage irrigation area were 2-3 times greater than in the groundwater irrigation area, indicating that sewage irrigation has had a significant impact on the contents of antibiotics in the soil. The elevation of antibiotic contents during the wet season is likely related to the fluctuating water level within the shallow vadose zone. The distribution of antibiotics is influenced by the flow direction of irrigation water. Moreover, the possibility of introducing antibiotics into the soil of the shallow vadose via the lateral recharge of sewage in the Beizhang Drainage Canal can not be excluded. Approximately $50 \%$ of Fluoroquinolones were reduced in the upper $50 \mathrm{~cm}$ of the soil zone and $70 \%$ at $80 \mathrm{~cm}$ depth. Tetracyclines may have experienced significant lateral migration. Macrolides and Sulfonamides (SMs) have similar soil profile distributions, with a concentration decrease down to $20 \mathrm{~cm}$ depth.
\end{abstract}

\section{Introduction}

China is an agricultural country, with agricultural irrigation accounting for more than $70 \%$ of total water use. The sources of irrigation water across China is quite complex. To make up for shortage of water, untreated sewage is used for irrigation purposes in northern China. This practice has a history of more than 40 years in Taiyuan City, but there are concerns that organic pollution from sewage irrigation could pose a threat to human health and ecological safety. Antibiotics are ubiquitous in the sewage and are a class of environmental contaminants that are not presently governed by regulation. The occurrence of antibiotics in sewage and groundwater in sewage irrigation in the Xiaodian area has been

\footnotetext{
* Corresponding author: lijiale39@126.com
} 
studied, however, the presence of antibiotics in the vadose zone in this area has not been investigated.

\section{Materials and methods}

The Xiaodian sewage irrigation area is located in Taiyuan City, Northern China. A detailed description of this area is given in previous studies [1-2]. To examine the environmental behavior of antibiotics in the shallow vadose zone, a transect of 4 shallow boreholes (labelled GS-1 to GS-4 in Fig. 1) and a shallow borehole (labelled GS-5 in Fig. 1) were located across the sewage irrigation area. As also shown in Figure 1, a nearby sample site (SW-1) is located in farm land at Liujian village and the groundwater irrigation area is located at a farm land at Wusu village.

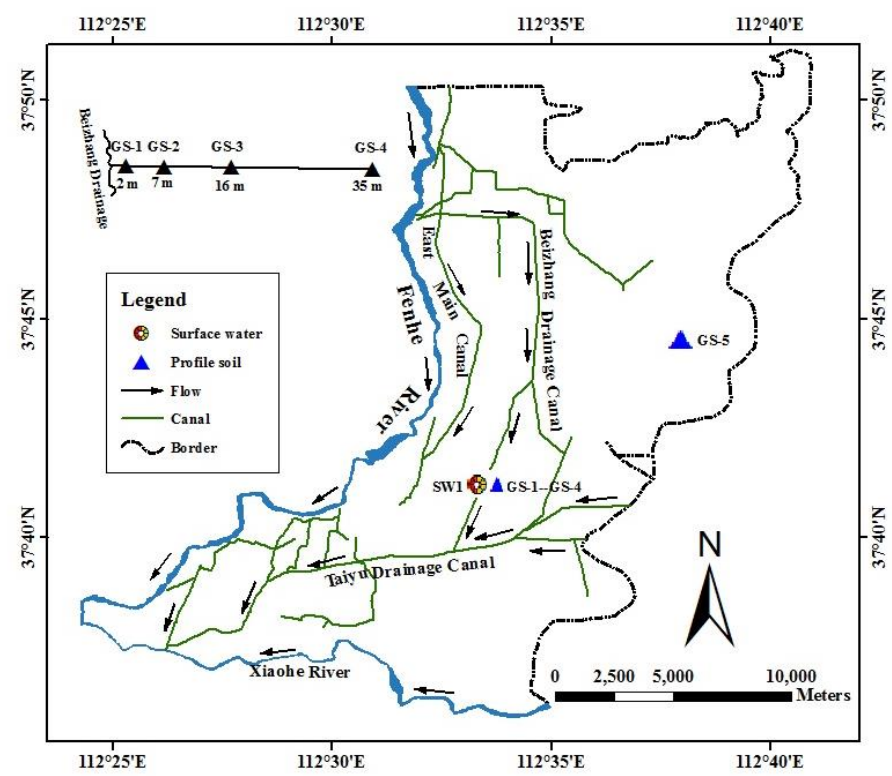

Fig. 1. Location of surface water and profile soil samples.

Four categories of antibiotics were analyzed by liquid chromatography coupled with tandem mass spectrometry as described in previous studies $[1,2]$ : (i) Sulfonamides (SMs): sulfapyridine (SPD), sulfathiazole (STZ), sulfamethoxazole (SMX), sulfamerazine (SMR), sulfamethazine (SMZ), sulfamethoxypyridazine (STP), sulfameter (SFM), sulfdiazine (SDZ); (ii) Fluoroquinolones (FQs): ofloxacin (OFL), lomefloxacin (LOM), ciprofloxacin (CIP), enrofloxacin (ENR), norfloxacin (NOR), sparfoxacin (SPA), gatifloxacin (GAT), fleroxacin (FLE), enoxacin (ENO); (iii) Macrolides (MLs): roxithromycin (RTM), clarithromycin (CTM), azithromycin (AZM), erythromycin (ERY); (iv) Tetracyclines (TCs): tetracycline (TC), oxytetracycline hydrochloride (OTC), chlorotetracycline hydrochloride (CTC), doxycycline hyclate (DOC).

\section{Results and discussion}

The contents of antibiotics in sewage and topsoil is given in Table 1. MLs and FQs comprise the greatest amounts of antibiotics. The contents of antibiotics in the transect GS1 to GS-4 were 2 to 3 times that measured in groundwater of the irrigation area $(364 \mathrm{ng} / \mathrm{g})$, 
indicating that sewage irrigation has a significant impact on the contents of antibiotics in soil. The contents of antibiotics in the GS-1 to GS-4 boreholes and in GS-5 are significantly higher than observed in other areas [4], and can even exceed the Maximum Contaminant Level (MCL) value of $100 \mathrm{ng} / \mathrm{g}$ [5]. FQs account for the greatest proportion of the total antibiotics in the vadose zone ( 82 to $95 \%$ ). This situation is different from that at SW-1, where the water level of the Beizhang Drainage Canal is lower than for GS-1 to GS-8, which is the deepest sample site of the transect. The elevation of antibiotic content within the vadose zone is likely a consequence of a rise in the water table during the wet season, when water level extends into the uppermost portions of the vadose zone sampled by the transect GS-1 to GS-4. The detected frequency of MLs is quite low, only occurred sporadically in soil close to surface, with no MLs detected in GS-5. SMs account for a very small proportion of the total antibiotic content of the Xiaodian soils; it is one order of magnitude lower in concentration than the TCs, and as much as two orders of magnitude lower than FQs.

Table 1. Contents of antibiotics in sewage (ng/L) and topsoil (ng/g).

\begin{tabular}{|c|c|c|c|c|c|c|}
\hline & SW-1 & GS-1 & GS-2 & GS-3 & GS-4 & GS-5 \\
\hline RTM & 6.50 & 0.05 & ND & 0.59 & 0.20 & ND \\
\hline AZM & 28.35 & $\mathrm{ND}^{\mathrm{a}}$ & ND & ND & ND & ND \\
\hline CTM & 8.58 & 0.14 & 0.29 & 0.64 & 0.18 & ND \\
\hline ERY & 249.65 & 0.91 & 56.72 & ND & 10.55 & ND \\
\hline$\sum \mathrm{MLs}$ & 293.07 & 1.10 & 57.01 & 1.23 & 10.94 & ND \\
\hline CTC & 34.13 & 28.97 & 36.30 & 25.75 & ND & 8.62 \\
\hline OTC & 14.91 & ND & ND & ND & ND & 13.13 \\
\hline $\mathrm{TC}$ & 23.13 & 2.86 & 10.04 & ND & 3.42 & ND \\
\hline DOC & ND & 28.45 & 47.66 & 15.76 & 12.14 & 2.95 \\
\hline$\sum \mathrm{TCs}$ & 72.18 & 60.28 & 94.01 & 41.51 & 15.56 & 24.70 \\
\hline SPA & 13.98 & 4.00 & 5.53 & 30.83 & 14.60 & 5.06 \\
\hline GAT & 2.39 & 20.04 & 20.66 & 6.78 & 32.71 & ND \\
\hline FLE & 2.03 & 144.70 & 118.03 & 55.20 & 58.10 & 30.36 \\
\hline OFL & 12.16 & 297.30 & 227.28 & 115.17 & 110.67 & 43.09 \\
\hline ENR & 0.85 & 323.02 & 306.40 & 283.25 & 168.19 & 94.03 \\
\hline LOM & ND & 35.60 & 29.11 & 10.97 & 25.97 & ND \\
\hline CIP & ND & 38.61 & 35.41 & 87.30 & 56.49 & 50.07 \\
\hline ENO & 179.30 & 48.95 & 58.23 & 102.94 & 80.40 & 51.05 \\
\hline NOR & 21.07 & 53.76 & 50.60 & 222.17 & 79.29 & 57.10 \\
\hline$\sum \mathrm{FQs}$ & 231.78 & 965.98 & 851.23 & 914.61 & 626.41 & 330.76 \\
\hline STP & 0.27 & 0.52 & 0.63 & 0.61 & 0.41 & ND \\
\hline SFM & 0.26 & 0.44 & 0.81 & ND & 0.75 & 0.41 \\
\hline SMZ & 1.92 & 0.51 & 3.32 & 0.64 & 0.49 & 0.21 \\
\hline SMR & ND & 0.42 & 0.36 & 0.53 & 0.36 & 0.42 \\
\hline STZ & ND & ND & ND & ND & ND & ND \\
\hline SMX & 16.61 & ND & 25.79 & 5.27 & 2.79 & 1.89 \\
\hline SDZ & 2.29 & 0.44 & 0.43 & 1.39 & 1.13 & 5.27 \\
\hline SPD & 1.51 & 0.37 & 0.37 & 0.79 & 0.60 & 0.26 \\
\hline$\sum \mathrm{SMs}$ & 22.86 & 2.70 & 31.70 & 9.23 & 6.54 & 8.46 \\
\hline SUM & 619.89 & $1,030.06$ & $1,033.95$ & 966.58 & 659.45 & 363.92 \\
\hline
\end{tabular}

a. ND: not detected or below the limit of quantification

For the transect GS-1 to GS-4, 24 different varieties of antibiotics were detected, with contents ranging from 104 to $1034 \mathrm{ng} / \mathrm{g}$, and 19 different antibiotics were detected with the range 114 to $364 \mathrm{ng} / \mathrm{g}$ at GS-5 These observations clearly indicate that sewage irrigation 
introduces greater amounts of many kinds of antibiotics into the shallow vadose soil than groundwater irrigation.

A contour map of total antibiotic content across the transect GS-1 to GS-4 is displayed in Figure 2. The highest antibiotic concentrations occur at the surface around GS-1. The source of this is sewage in the Beizhang Drainage Canal during the wet season. There is a trend of decreasing antibiotic concentrations from west to east across the transect in the direction of irrigation water flow. There is a possibility that antibiotics could be introduced into the shallow vadose soil via lateral recharge of sewage from the Beizhang Drainage Canal. The antibiotic content also decreases from the top to the bottom of the profile. This indicates that the transport of antibiotics also be influenced by leaching from the uppermost portions of the vadose zone. Compared with the groundwater irrigation area (Fig. 3), there is similar trend of decreasing FQs with depth, 66\% of FQs have been reduced in the $80 \mathrm{~cm}$ while TCs and SMs contents have been reduced by $96 \%$ and $95 \%$, respectively. ML contets at all depths are below detection levels.

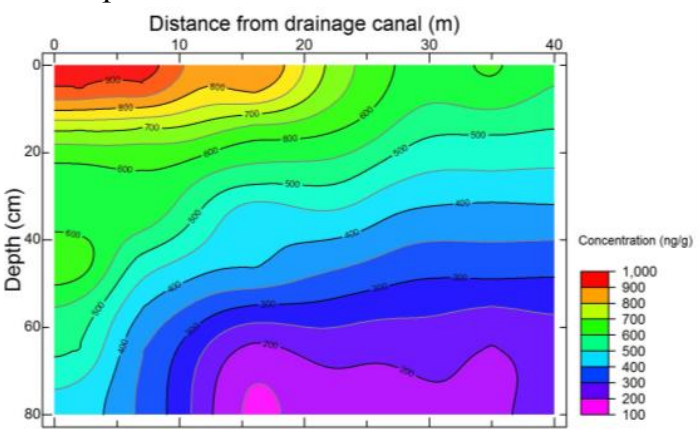

Fig. 2. Contour map of total antibiotic content in the transect GS-1 to GS-4. The Beizhang drainage canal is located at the left side of the profile.

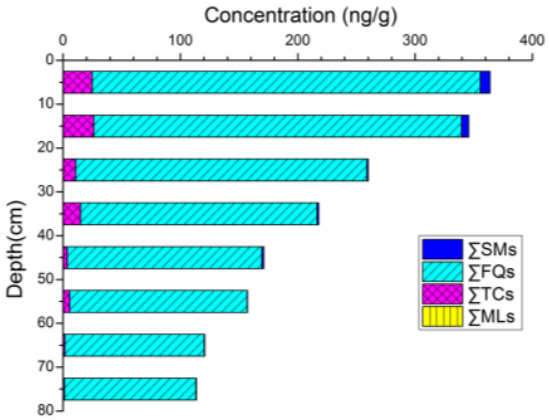

Fig. 3. The distribution of antibiotics in the shallow vadose zone of groundwater irrigation area. MLs were not detected.

Figure 4 shows the differing behavior of the four categories of antibiotics across the transect GS-1 to GS-4. The contour of FQs is quite similar to that of the total antibiotics, this is because FQs account for 76 to $98 \%$ of the total antibiotic content measured. As is the case with total antibiotic content, the concentration of FQs decreases eastward across the transect and with depth. Approximately 50\% of the FQs were within the upper $50 \mathrm{~cm}$, which reached a reduction of and $70 \%$ by $80 \mathrm{~cm}$ depth.

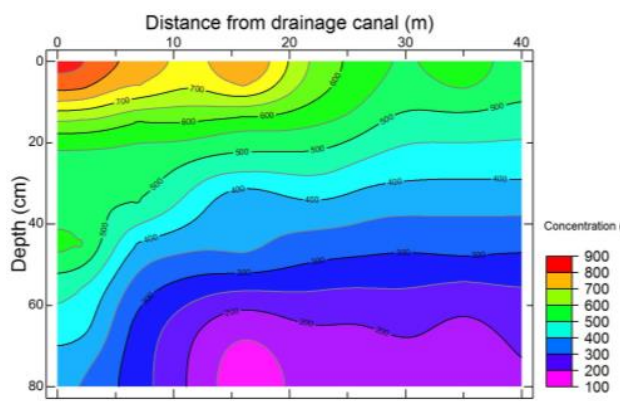

A

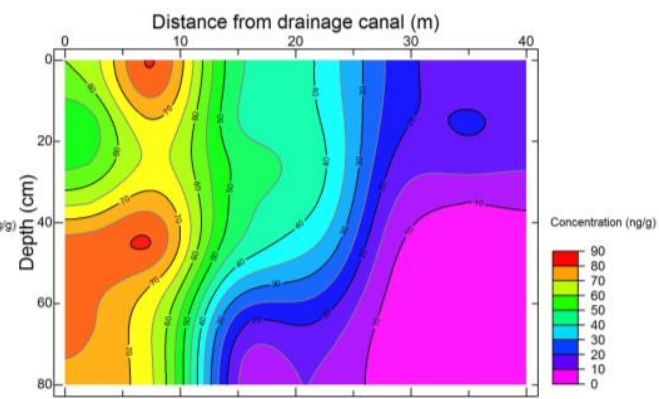

B 

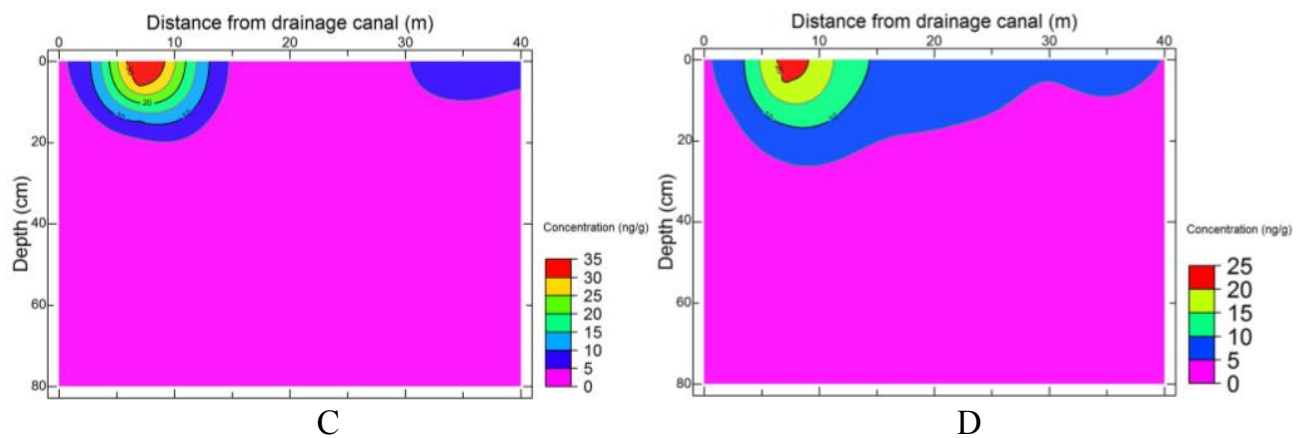

Fig. 4. The contour map of four categories of antibiotics across the transect GS-1 to GS-4 ; $\mathrm{A}=\mathrm{FQs}, \mathrm{B}=\mathrm{TCs}, \mathrm{C}=\mathrm{MLs}, \mathrm{D}=\mathrm{SMs}$.

TCs are the second most abundant class of antibiotics observed. By contrast with FQs, TCs exhibit a significant lateral migration. Their concentration decreases primarily in the horizontal direction, indicating that TCs may have experienced significant lateral migration. MLs and SMs have similar distribution profiles across the GS-1 to GS-4 transect. The decrease in their concentrations occurs in the upper $20 \mathrm{~cm}$ of the soil. Results from an other study shows that SMs have a low sorption potential and is, therefore, likely to be highly mobile [6]. Up to $110 \mathrm{ng} / \mathrm{g}$ of sulfamethazine was observed in the surface soil in peri-urban Beijing [7], with significant migration of particular the SMs down into the deep subsoil $(\geq 2 \mathrm{~m}$ ) on agricultural fields, and even down to $4 \mathrm{~m}$ at waste disposal sites. However, there only $5 \mathrm{ng} / \mathrm{g}$ of SMs was detected below $20 \mathrm{~cm}$ depth in this study, which is probably because the content of SMs in sewage and manure is quite low and, therefore, less SMs migration into the deeper soil.

\section{Conclusions}

MLs and FQs were the main antibiotics in the shallow vadose zone. The contents of antibiotics in the profile nearby sewage irrigation area were 2 to 3 times as those in groundwater irrigation area, indicating that sewage irrigation has a significant impact on the contents of antibiotics in the soil. The elevation of their contents in the wet season could be related to that of water level. The distribution of antibiotics was influenced by the irrigation flow direction. Moreover, the possibility of introducing antibiotics into the shallow vadose soil via the lateral recharge of sewage in the Beizhang Drainage Canal could not be excluded. Some $50 \%$ and $70 \%$ of the FQs was reduced at the upper $50 \mathrm{~cm}$ and $80 \mathrm{~cm}$ depth, respectively. TCs may have experienced significant lateral migration. MLs and SMs has a similar distribution on the profile. The decrease of their contents occurred in the upper $20 \mathrm{~cm}$.

Acknowledgments. The authors would like to thank Prof. Y. Wang for support and assistance. This study was financially supported by Water Resources and Water Environment Research Center Foundation of Water Resources Ministry in China (Grant No. ZXKT201709), Natural Science Foundation of China (Grant Nos. 40830748, 41772266, and 51861145308), Science and Technology Project Fund of Jiangxi Provincial Education Department (Grant No. GJJ170443).

\section{References}

1. J. Li, China University of Geosciences, Wuhan (2015)

2. J. Li et al., IOP Conf Series: Earth Env Sci, 146, 1-6 (2018) 
3. J. Li, et al., Proc 9th IAHS Conf on Groundwater Quality, 42 (2016)

4. X. Pan et al., J Ecol Rural Env (in Chinese), 28, 518-525 (2012)

5. VICH, European Agency for the Evaluation of Medicinal Products (2000)

6. A. Boxall, et al., Toxicol Lett, 131, 19-28 (2002)

7. A. Ostermann, et al., Env Monit Assess, 186, $7693-7707$ (2014) 